\title{
nature
}

cell biology

\section{Developing open access}

A major argument in the recently re-invigorated open access debate is the importance of providing scientists in less developed countries with access to scientific information. This is indeed an important issue, as subscription to multiple journals can easily become prohibitive for the stretched budgets of many academic institutions in such countries. However, 'author pays' models of financing journals only provide superficial solutions to the problem: although they allow free access to the reader, they might well prevent the publication of research originating in developing countries from authors that cannot finance the page or submission charges. Nature Cell Biology and its siblings do not levy basic page charges, and the journal has always followed a policy of waiving any additional production charges that may arise for authors demonstrably facing budgetary constraints.

Nevertheless, the only way to invigorate scientific development in less affluent regions is to completely open journals to both the authors and the readers of these countries. In view of this need, Nature Publishing Group is participating in two projects - Hinari and SciDev.Net. —aimed at providing such countries with the chance to develop from within.

\section{HINARI}

HINARI (Health InterNetwork Access to Research Initiative (http://www.healthinternetwork.org/index.php)) is the rather cumbersome acronym of a recent United Nations initiative led by the World Health Organization in collaboration with a number of scientific publishers. The project provides free online access to the entire content of all Nature family titles as part of a growing list of around 2,000 publications. The focus is on medical research and health information, an obvious primary need of developing countries. An agricultural counterpart with the equally involved acronym AGORA (Access to Global Online Research in Agriculture (www.aginternetwork.org/en/about.php)) was launched by the UN in October with a very similar aim and scope.

HINARI is clearly striking a chord: over a thousand academic and government institutions from a hundred countries had registered at the time of going to press and significant internet traffic demonstrates active use. This list is likely to grow significantly, as countries with a GNP-per-capita below $\$ 3000$ are eligible for free access to all NPG content $(69$ counties with GNP below $\$ 1000$ receive free access to all participating publications, with a further 44 receiving highly discounted or free rates). The list includes countries whose researchers and policy makers need access to health-related literature, such as much of the African sub-continent, as well as countries with fledgling research programmes such as the Ukraine, Latvia and the West bank/Gaza.

Expansion of the model to link access discounts to GNP further up the ladder would be most welcome, but obviously requires careful ongoing evaluation of the economic impact on publishers.

\section{SCIDEV.NET}

Given recent dramatic developments in the availability of information technology, the web offers a real chance for developing nations to

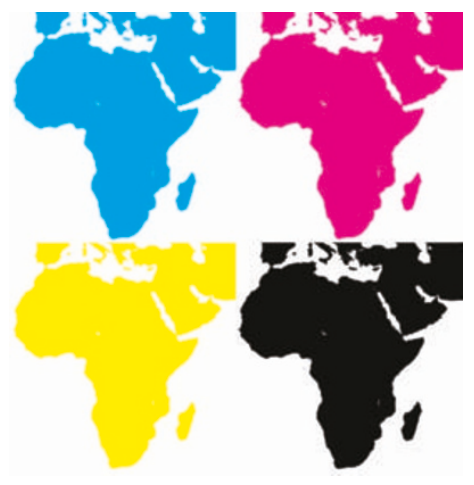

actively benefit from and participate in the scientific community. The Science and Development Network (SciDev.Net) project aims to catalyse this process. The self-proclaimed goal of the London-based freeaccess website is to "provide authoritative information on science and technology-related issues that impact the economic and social development of developing countries". However, the two-year-old project aims to go further by actively nucleating scientific events and regional networks in the developing world; to date, networks exist for Latin American and sub-Saharan African. Although editorially independent, the project receives financial support from the UK, Swedish and Canadian departments of international development, and the Rockefeller foundation. It also benefits from the active participation of Nature Publishing Group at various levels, including selected free content from Nature. The website has grown into a bona fide weekly journal with an ambitious editorial scope, including news, features, opinions and interviews, and a breadth of subject range to match. Indeed, the website also offers more detailed information on HINARI and other open-access initiatives.

\section{Not all human cloning is alike}

The UN has been pondering a treaty on human cloning for over two years. Earlier in November, the general assembly finally passed over the chance to make a decisive move on this charged subject by voting narrowly in favour of a motion to delay any decision for another two years. This was clearly a diplomatic compromise that simply defers the issue in the hope that a clearer consensus may emerge. This was probably a wise move given the intense lobbying of influential powers, such as the catholic church and the US government, in favour of a blanket ban on all forms of human cloning, including therapeutic cloning in addition to reproductive cloning. Banning therapeutic cloning would be a dramatic setback to scientific research and the associated potential medical benefits associated with stem-cell therapies. Studies such as one by Helen Blau and colleagues in the last issue of NCB (DOI: $10.1038 /$ ncb 1053) support the notion that it is essential to explore the potential of embryonic stem cells. However, this UN vote was clearly a missed opportunity to ensure that reproductive human cloning is definitively banned across the globe. 